\title{
Editorial
}

\section{Editorial: Keeping Antarctic Science relevant to and representative of the international Antarctic research community}

$I^{t}$ $\mathrm{t}$ is already something over a year since I took over the role of Editor in Chief for Antarctic Science, a year which has turned expectations and opportunities upside down and from which I doubt any of us have escaped the impacts, both personal and professional. The end of 2020 saw our long-standing Managing Editor, Sharon Cooke, step down from the role, and I take this opportunity to thank her for her commitment and service to the journal since its earliest days. I also thank Sharon for continuing through 2020 and helping me find my feet here, and then providing a good handover to our new Managing Editor Mariel Kieval, who it is also a great pleasure to welcome!

The Antarctic research community faces particular challenges from the pandemic, imposed both through the necessary and drastic access restrictions to Antarctica itself and as a consequence of the exceptional level of direct international interaction and cooperation that normally characterises much Antarctic research. As with the entire scientific community, we are having to find new ways of working and reshaping our priorities but here, perhaps, we have an inherent advantage as, integral to most successful polar research, is the need for flexibility and opportunity taking. One way that this is being expressed, certainly if my own colleagues and international collaboration network are anything to go by, is through turning to publication - indeed to the extent that institutional publication budgets are even being stretched!

That can be no bad thing for an academic journal such as Antarctic Science, but no journal can afford to stand still! The past year has given opportunity, in discussion with the management board of Antarctic Science Ltd and our publisher CUP, to take stock of how we are achieving our aims and, looking to the future, how to develop the journal's profile, standing and engagement with the entire Antarctic research community. As a journal, we are very privileged to enjoy a close relationship with SCAR, and a key aim is to be a suitable target journal for paper submissions across the diversity of Antarctic and related science that SCAR supports and from the entire international research community. Antarctic Science Ltd sponsors the 'David Walton Antarctic Science Lecture' (named in honour of our late founding editor and highly active member of the Antarctic community, David Walton) at the SCAR Open Science Conference. It also runs the Antarctic Science Bursary Scheme, through which we reinvest the journal surplus to support early career researchers across the international Antarctic community in developing their skills and experience.

We recognise the exciting ways in which Antarctic science is evolving, in particular encouraging the development and integration of an active humanities and social science community, and in the emphasis in the new generation of SCAR scientific programmes of effective engagement with Antarctic governance mechanisms in order to achieve the aspiration of 'science into policy'. It is timely to re-emphasise that Antarctic Science is a multi-disciplinary journal that welcomes submissions across the entire breadth of Antarctic research. To that end, the eagle-eyed will spot over the next few months that we are expanding and refreshing the journal's editorial board to ensure we better represent the contemporary research community in terms of both disciplinary coverage and inclusivity, in order to encourage submissions from all parts of it. Antarctic Science, perhaps more than most journals, faces a particular challenge in facilitating and supporting submissions from authors whose primary language is not English, given the ever-expanding multinational composition of the Antarctic community. While science quality must remain the benchmark of the reviewing and publication process, we are actively seeking ways to improve linguistic support for authors in the submission and review process.

Having now moved to online-only publication, the journal is also expanding the range of paper types considered for publication and relaxing some formatting requirements, ranging across standard research papers, short communications, full reviews, syntheses and opinion papers. We will continue to welcome unsolicited submissions across all paper categories, as well as proactively seeking contributions such as reviews in particular areas or opinion papers addressing topical Antarctic issues, and welcoming preliminary enquiries about prospective submissions. The journal has a record of providing stimulating and though-provoking editorials, and strongly welcomes offers of 'guest' editorials. The structure of the Antarctic research community, both within SCAR and at national and regional levels, lends itself to structured compilations of articles, and we welcome proposals for such compilations as special issues. They might provide a particularly attractive option, for instance, to advertise the achievements of groups or programmes within SCAR and other collaborative scientific initiatives, provide a focus on a specific Antarctic research activity, or highlight the achievements of the different national programmes.

Peter Convey 